\title{
АКТУАЛЬНЫЕ СПОРЫ СУДОВ АПЕЛЛЯЦИОННОЙ ИНСТАНЦИИ В СВЯЗИ С ПРИМЕНЕНИЕМ ЗАКОНОДАТЕЛЬСТВА И МЕР ПО ПРОТИВОДЕЙСТВИЮ РАСПРОСТРАНЕНИЮ НА ТЕРРИТОРИИ РОССИЙСКОЙ ФЕДЕРАЦИИ НОВОЙ КОРОНАВИРУСНОЙ ИНФЕКЦИИ (COVID-19)
}

\section{CURRENT DISPUTES OF THE COURTS OF APPEAL IN CONNECTION WITH THE APPLICATION OF LEGISLATION AND MEASURES TO COUNTER THE SPREAD OF A NEW CORONAVIRUS INFECTION (COVID-19) IN THE TERRITORY OF THE RUSSIAN FEDERATION}

A. Lysak

Summary. The article analyzes the judicial practice of the courts of appeal of the most problematic disputes arising in connection with the application of legislation and measures to counter the spread of a new coronavirus infection (COVID-19) in the territory of the Russian Federation. A study was carried out on the plurality of adopted normative legal acts, the urgency of publication and publication, the reaction of society to legal innovations, the unpreparedness of Russian law and the crisis caused by the coronavirus pandemic and the fight against it, the lack of uniformity of law enforcement practice. The arisen problems of the judicial system are described. Increase in the number of pending cases in certain categories of disputes. Missing procedural deadlines due to the introduction of additional restrictive measures to reduce the risks of the spread of COVID-19, aimed at ensuring the sanitary and epidemiological well-being of the population on the territory of the Russian Federation. The perception of society is reflected in the introduction of a special legal regime that provides for restrictions on the free movement of citizens, their presence in public places, state and other institutions, imposing public-law duties on citizens, without declaring an emergency. A special approach of law enforcement practice on labor disputes, disputes arising from contractual relations, family disputes, according to the statistical data of the bases of the courts of appeal, is considered. Legal conflicts of the adopted legislative norms are shown. The further development of the activities of the courts of appeal in Russia and the judicial system as a whole is predicted.

Keywords: courts of appeal; new coronavirus infection (COVID-19); restrictive measures; pandemic; trial.

\author{
Лысак Анастасия Николаевна \\ Аспирант, Московский гуманитарный университет \\ Rodnikurist@mail.ru
}

Аннотация. В статье анализируется судебная практика судов апелляционной инстанции наиболее проблематичных споров, возникших в связи с применением законодательства и мер по противодействию распространению на территории Российской Федерации новой коронавирусной инфекции (COVID-19). Проводилось исследование множественности принимаемых нормативно-правовых актов, срочность издания и публикации, реакция общества на правовые нововведения, не подготовленность российского права и кризис, вызванный пандемией коронавируса и борьбы с ним, отсутствие единообразия правоприменительной практики. Описаны возникшие проблемы судебной системы. Увеличение количества рассматриваемых дел по отдельным категориям споров. Пропуски процессуальных сроков, в связи с введением дополнительных ограничительных мер по снижению рисков распространения COVID-19, направленных на обеспечение санитарно-эпидемиологического благополучия населения на территории Российской Федерации. Отражается восприятие общества на введение особого правового режима, предусматривающего ограничения в свободном перемещении граждан, их нахождение в общественных местах, государственных и иных учреждениях, возложение на граждан обязанностей публично-правового характера, без объявления чрезвычайной ситуации. Рассмотрен особый подход правоприменительной практики по трудовым спорам, спорам, вытекающим из договорных отношений, семейные споры, согласно статистическим данным баз апелляционных судов. Показаны правовые коллизии принимаемых законодательных норм. Спрогнозировано дальнейшее развитие деятельности апелляционных судов в России и судебной системы в целом.

Ключевые слова: суды апелляционной инстанции; новая коронавирусная инфекция (COVID-19); ограничительные меры; пандемия; судебный процесс. 


\section{Ввемение}

елью исследования послужило стихийное, вероломное вторжение возникшей в конце 2019 года пандемии, вызванной распространением новой коронавирусной инфекции (COVID-19) во всем мире.

Жизнь, социальное пространство, экономика и право меняются ежедневно - «Новое время», «Новая реальность».

Период с конца 2019 года начало пандемии, и, к сожалению, в настоящее время окончание периода не определено, навсегда войдет в историю как наиболее ужасающее, смертоносное время. И наверняка в дальнейшем будет обозначено как «биологическая война», перевернувшая и затронувшая весь мир в целом.

Почти два года этого «нового времени» становится понятно, что жизнь не будет прежней. Главным становится научиться жить в «новой реальности». Воспринимать не критически, а с пониманием важности сохранения человеческого ресурса. Принимать любые изменения как парадигму сохранения мира, и какими бы не были правовые изменения, их нужно воспринимать с огромной социальной ответственностью.

Статья посвящена изменению законодательства Российской Федерации, в связи с принятием мер по противодействию распространению на территории Российской Федерации новой коронавирусной инфекции (COVID-19).

Особое внимание в статье посвящается судебной системе, а именно деятельности апелляционных судов Российской Федерации, аналитике рассматриваемых судебных споров. Поставлены проблемные вопросы судебной системы, спрогнозированы пути их решения.

31 декабря 2019 года власти Китая проинформировали Всемирную организацию здравоохранения о вспышке неизвестной пневмонии в городе Ухань в центральной части страны (провинция Хубэй). Специалисты установили, что возбудителем болезни стал новый коронавирус, позже заболевание получило официальное название COVID-19.

11 марта Всемирная организация здравоохранения объявила вспышку нового коронавируса COVID-19 пандемией.

В России «Первый случай был 1 марта, если не считать двух завозов из Китая в феврале»,- объявила глава Роспотребнадзора Анна Попова на совещании о санитарно-эпидемиологической обстановке с участием президента.
Согласно критериям ВО3, пандемия (греч. $\pi \alpha v \delta \eta \mu i ́ \alpha-$ «весь народ») - высшая степень развития эпидемического процесса, вирус, распространившийся в мировом масштабе при отсутствии вакцины и препаратов его профилактики и лечения, к которому большинство людей планеты не обладают иммунитетом. Потенциально тяжелая острая респираторная инфекция, вызываемая коронавирусом SARS-CoV-2 (2019-nCoV), представляет собой опасное заболевание, которое может протекать как в форме острой респираторной вирусной инфекции легкого течения, так и в тяжелой форме; ее специфические осложнения могут включать вирусную пневмонию, влекущую за собой острый респираторный дистресс-синдром или дыхательную недостаточность с риском смерти. Против болезни отсутствуют какие-либо специфические противовирусные средства лечения или профилактики. По мнению ВО3, призывающей страны к решению о необходимости обеспечения социального дистанцирования и принятию иных адекватных ситуации мер, это первая в истории человечества пандемия, которая может быть взята под контроль странами мирового сообщества под эгидой Организации Объединенных Наций (BО3, 2020).

Государство и российское общество столкнулись с новым вихрем непредсказуемых событий. Россия, как и многие другие страны, оказалась абсолютно не готовой к такому стечению обстоятельств, ни со стороны здравоохранения, ни со стороны социально-экономического развития, и крайне сложным и запутанным стало правовое пространство.

Первое обращение Президента Российской Федерации В.В. Путина по вопросу сложившейся ситуации с эпидемией коронавируса в мире, состоялось 25 марта 2020 года, на основании ст. 80 Конституции Российской Федерации возложил на высших должностных лиц (руководителей высших исполнительных органов государственной власти) субъектов Российской Федерации, исходя из санитарно-эпидемиологической обстановки и особенностей распространения инфекции в конкретном регионе, обеспечение разработки и реализации комплекса ограничительных и иных мероприятий в том числе в условиях введения режима повышенной готовности, чрезвычайной ситуации.

С этой даты логично обозначить начало принятия особых правовых и социально-эпидемиологических, экономических режимов.

Ситуация в мире по коронавирусу развивалась настолько стремительно, что законодательные акты принимались стихийно по правовому смыслу, но с временным пробелом, следовательно, возникало непонимание, неверное толкование правовых норм и как следствие неверное практическое применение. 
Цели, задачи, поручения, обозначенные выступлением Президента значительно позже зафиксированы в Указе Президента РФ от 02.04.2020 № 239 «О мерах по обеспечению санитарно-эпидемиологического благополучия населения на территории Российской Федерации в связи с распространением новой коронавирусной инфекции (COVID-19)».

Федеральный закон от 21 декабря 1994 года N68-Ф3 «О защите населения и территорий от чрезвычайных ситуаций природного и техногенного характера» определяет единую государственную систему предупреждения и ликвидации чрезвычайных ситуаций, объединяет органы управления, силы и средства федеральных органов исполнительной власти, органов исполнительной власти субъектов Российской Федерации, органов местного самоуправления, организаций, в полномочия которых входит решение вопросов по защите населения и территорий от чрезвычайных ситуаций, и функционирующую в одном из трех режимов - повседневной деятельности, повышенной готовности, чрезвычайной ситуации (ст. 6).

Однако с наступлением в России пандемии, вызванной распространением коронавирусной инфекции, закрепленное в ст. 1 указанного Закона определение понятия чрезвычайной ситуации было дополнено признаком «распространения заболевания, представляющего опасность для окружающих» как возникшей обстановки на определенной территории.

К сожалению дефиниции «повышенной готовности» названный Закон не содержит. Пандемия, вызванная распространением новой коронавирусной инфекции, не содержит правовых признаков возникновения чрезвычайных ситуаций природного и техногенного характера, и не порождает порядка организации деятельности органов управления и сил единой государственной системы предупреждения и ликвидации чрезвычайных ситуаций, комплексом правовых механизмов, взаимодействующих между собой необходимых запретов, ограничений, обязываний или дозволений.

Последующее правовое регулирование осуществляется не на Федеральном уровне, а в большинстве на региональном (Постановления, Указы, Распоряжения), в режиме ежедневных поправок и дополнений.

\section{$\triangle$ елтельность су $\triangle \mathrm{OB}$$$
\text { суАебной системы России }
$$$$
\text { с начала панАемии }
$$

Постановлением Президиума Верховного Суда РФ, Президиума Совета судей РФ от 18.03.2020 N808<0 приостановлении личного приема граждан в судах> работа судов переведена в особый режим в период с 19 марта 2020 года по 10 апреля 2020 года (включительно). Так, с началом пандемии в судах приостановлен личный прием граждан и подача документов возможна только через электронные интернет-приемные судов или по почте России. С введением особого режима рассматриваются только категории дел безотлагательного характера (об избрании, продлении, отмене или изменении меры пресечения, о защите интересов несовершеннолетнего или лица, признанного в установленном порядке недееспособным, в случае отказа законного представителя от медицинского вмешательства, необходимого для спасения жизни, и другие), а также в порядке приказного, упрощенного производства.

Ранее запланированные реформы в деятельности судов России, были реализованы в кратчайшие сроки, в том числе цифровизация. Теперь рекомендовано было судам при наличии технической возможности инициировать рассмотрение дел путем использования систем видеоконференц-связи. Ограничен доступ в суды лиц, не являющихся участниками судебных процессов.

Практика, рассмотрения дел в период пандемии определялась индивидуально, отсутствует единый подход.

Критерий «безотлагательности» не имеет четко прописанных характеристик определения рассмотрения дела данной категории.

Наиболее часто рассматриваемые дела об административных правонарушениях за соблюдением законодательства в области санитарно-эпидемиологического благополучия населения. По трудовым спорам большой процент рассматриваемых дел о восстановлении на работе и выплате заработной платы, а также практико-применение нововведений, связанных с внесением поправок в Трудовое законодательство о дистанционной работе. Споры, вытекающие из хозяйственной деятельности юридических лиц, согласно разъяснениям Верховного суда, пандемия не признана форс-мажорным обстоятельством. В октябре 2020 года Пленумом Верховного Суда внесены в Госдуму проекты поправок Уголовного кодекса Российской Федерации и Уголовно-процессуального кодекса Российской Федерации, в связи с введением уголовного проступка. Поправки направлены на гуманизацию законодательства.

Трудности выработки дефиниции принимаемых поправок и изменений законодательства в период пандемии, особенно с отлагательным фактором публикаций, привело к динамичной судебной практике. 
За год со дня начала работы «новых» апелляционных судов общей юрисдикции, значительно повысилась эффективность правосудия. Количество удовлетворенных жалоб в гражданском судопроизводстве увеличилось с 4\% до 13\%, в административном судопроизводстве - с 3\% до 16\%, в уголовном судопроизводстве - с 8\% до 12\%, поделился статистикой глава ВС на Пленарном заседании.

Успешное освоение программных средств обеспечивающих удаленную работу, видеоконференции и цифровизация в период пандемии, обеспечат в будущем переход судебной системы полностью на электронный формат. Цифровизация правосудия значительно повысит уровень и качество судопроизводства, ускорение, сокращение сроков рассмотрения. Переход на электронные документы снизит трудозатраты работников аппарата суда.

Общество с развитием цифровых технологий было настроено на переход к цифровизации. Пандемия ускорила этот процесс.

\section{ЛИТЕРАТУРА}

1. Официальный сайт Всемирной организации здравоохранения. URL: https://www.who.int/ru/emergencies/diseases/novel-coronavirus-2019?gclid=CjwKC Ajwg0GCBhAIEiwA7FUXkiB3XqVysH4TpgeZvgVIche5-PnLBjcb5ygaRx3Sk-rtJhbgh7JrbxoCLtMQAvD_BwE (дата обращения: 22.03.2021).

2. Федеральный закон от 21 декабря 1994 года N68-Ф3 «0 защите населения и территорий от чрезвычайных ситуаций природного и техногенного характера»// СПС Консультант Плюс.

3. Постановление Президиума Верховного Суда РФ, Президиума Совета судей РФ от 18.03 .2020 N808 «0 приостановлении личного приема граждан в судах» // СПС Консультант Плюс.

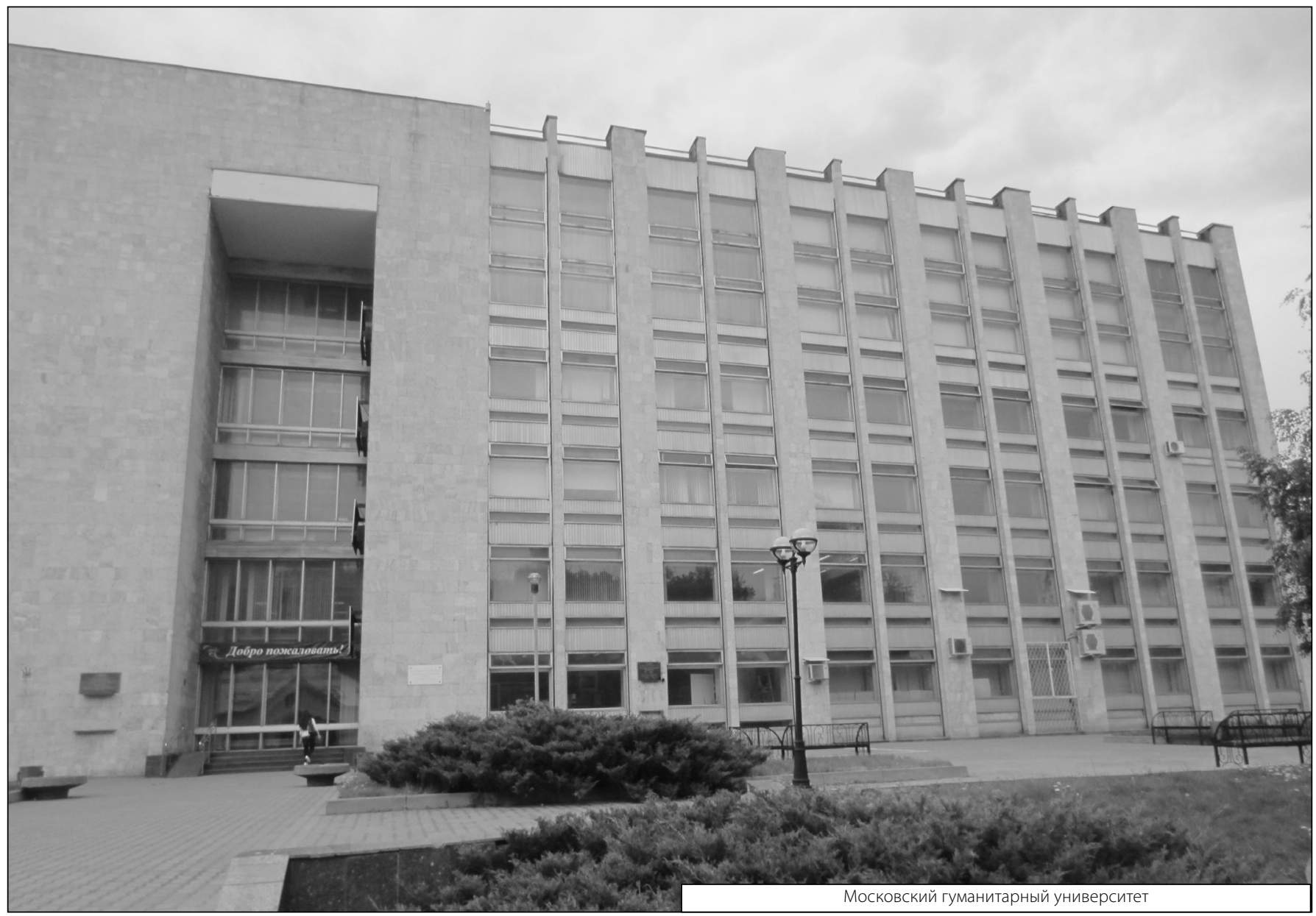

